\title{
Separation of Nitrogen Heterocyclic Compounds from Model Oils by an Emulsion Liquid Membrane
}

\author{
Hiroaki HABAKI, Yoshiyuki SHIMADA and Ryuichi EGASHIRA* \\ Department of International Development Engineering, \\ Tokyo Institute of Technology, 12-1, O-okayama-2-chome, \\ Meguro-ku, Tokyo 152-8550, Japan \\ (Received March 28, 2014; Accepted May, 30, 2014)
}

The separation of nitrogen heterocyclic compounds by an $(\mathrm{O} / \mathrm{W}) / \mathrm{O}$ emulsion liquid membrane was studied. Quinoline and 2-methylnaphthalene were selected as the representative components of nitrogen heterocyclic and homocyclic compounds, and a toluene or heptane solution of these two compounds was used as the model feed oil. Deionized water or an aqueous solution of 1,3-butandiol was used as the membrane solution. Quinoline preferably permeated through the emulsion liquid membrane and could be separated from 2-methylnaphthalene in the model feed oils. The addition of 1,3-butandiol in the membrane solution could enhance the permeation rates. The separation selectivity of quinoline relative to 2-methylnaphthalene was larger with the toluene feed oil compared with the heptane solution.

\section{Introduction}

Some nitrogen heterocyclic compounds are useful as intermediates for the production of agricultural chemicals, medicines, perfumes, and many other useful chemicals. Coal tar and some coal-derived oils are regarded as the possible sources for these valuable nitrogen heterocyclic compounds. On the other hand, some fractions produced from petroleum refinery processes also contain these compounds which occasionally cause some trouble by reducing the catalytic efficiency or shorten its lifetime, and degradation in the quality of the fuel oils due to autoxidation or chemical reaction during storage [1]. Hydrotreatment is the most popular way to remove these components, which effectively decomposes the components but the process is expensive and consumes much hydrogen [1,2]. For both type of oils, effective techniques to separate the heterocyclic compounds have been expected to develop. To recover these compounds, acidic and basic extraction was reported [3], and some drawbacks were pointed out, such as corrosion of the equipment, difficulties in solvent recovery, and so on. As alternative methods, ordinary liquid-liquid extraction without reaction [4-7] and (O/W)/O liquid membranes [9-11] have been studied. In these reports, catalytically cracked diesel oil, light cyclic oil, and coal tar absorption oil were used as source oils for the nitrogen heterocyclic compounds. In a study of the separation of coal tar absorption oil, the distribution coefficients of nitrogen heterocyclic and aromatic compounds were measured, in which water and coal tar absorption oil diluted by toluene or heptane were used as the aqueous and organic phases to select the favorable extract phase for the emulsion liquid membrane separation. The distribution coefficients of quinolone, indole and methylnaphthalene were affected by the diluents and were larger with heptane as the 
extract phase than those with toluene [11]. However, the effects of the diluents or of the major component in the feed phase on the $(\mathrm{O} / \mathrm{W}) / \mathrm{O}$ emulsion liquid membrane permeation have not been reported yet.

In this work, toluene or heptane solutions of quinoline and 2-methylnaphthalene were used as model feed oils to study the effects of the type of feed solution on the separation of nitrogen heterocyclic compounds by the $(\mathrm{O} / \mathrm{W}) / \mathrm{O}$ emulsion liquid membrane technique. Coal and petroleum derived oils are generally rich in aromatic and paraffin components, and the feed solutions of toluene and heptane were prepared to simulate these oils. First the liquid-liquid equilibrium was measured with the model feed oils and the emulsion liquid membrane separations were carried out under various conditions.

\section{Experimental}

\subsection{Liquid-liquid equilibrium}

The experimental conditions for the batch liquid-liquid equilibrium studies are shown in Table 1. Two types of model mixtures were used as the feed organic phases. Quinoline and 2-methylnaphthalene were selected as representative dicyclic compounds of nitrogen heterocyclic and homocyclic compounds, which were reported to be contained in coal tar adsorption oil [6] and catalytically cracked oil [4]. The mixture of quinoline and 2-methylnaphthalene was diluted with toluene, Feed 1, or heptane, Feed 2, to represent the feed oil of an aromatic or paraffin rich fraction. Deionized water or an aqueous solution of 1,3-butandiol was used as the aqueous phase. 1,3-Butandiol was selected to enhance the solubility of the organic compounds, especially the nitrogen heterocyclic compounds $[8,10]$. All the chemicals used were of analytical grade. The specified amounts of feed organic and aqueous phases, $R_{0}$ and $E_{0}$, were brought into contact in an Erlenmeyer flask in a constant temperature shaker at $298 \mathrm{~K}$. After equilibrium, the organic and aqueous phases, $R_{1}$ and $E_{1}$, were split using a separation funnel. The obtained phases were analyzed using a commercial gas chromatograph with a flame ionization detector, (GC-2010, Shimadzu Corp.) to determine the compositions in both phases.

\subsection{Emulsion liquid membrane permeation}

The principal experimental conditions of the $(\mathrm{O} / \mathrm{W}) / \mathrm{O}$ emulsion liquid membrane permeation are summarized in Table 2. The toluene or heptane solutions of quinoline and 2-methylnaphthalene was used as the feed oils for Feed 1 or Feed 2, the same as was used in the liquid-liquid equilibrium measurements. Aqueous membrane solutions were prepared from deionized water, plus saponin as an emulsifying agent, and 1,3-butandiol as an additive to enhance the permeation rate. All the chemicals used were also of analytical grade. The initial mass fraction of the additive in the membrane solution was fixed as 0.25 . The feed oils and the aqueous membrane solutions were emulsified by the commercially available homogenizer (MULTIDISPERSER PB-95, SMT Co. Ltd.). The prepared emulsions were contacted with the solvents in a stirred vessel, made of Pyrex glass equipped with a six-flat-blade turbine type impeller and four baffles, the same apparatus as used in the previous study [11]. Toluene or heptane was used as the solvents for the feed oils of Feed 1 or Feed 2, respectively. The time to start the stirring in the vessel was defined as $t=0 \mathrm{~h}$. After a specified contacting time, the extract was analyzed by the same gas chromatograph as used in the liquid-liquid equilibrium measurement, in order to determine the composition in the extract. The demulsification of the obtained emulsion was not carried out and the composition in the raffinate was calculated by the mass balance equation based on the analysis of the extract. A tracer to detect membrane instability was not used in these 
measurements. According to our previous studies [11, 12], the effects of membrane instabilities due to membrane breakage and mechanical entrainment rates were very small relative to the permeation rate. Thus the effects of the membrane instabilities were considered to be negligible in this study as well.

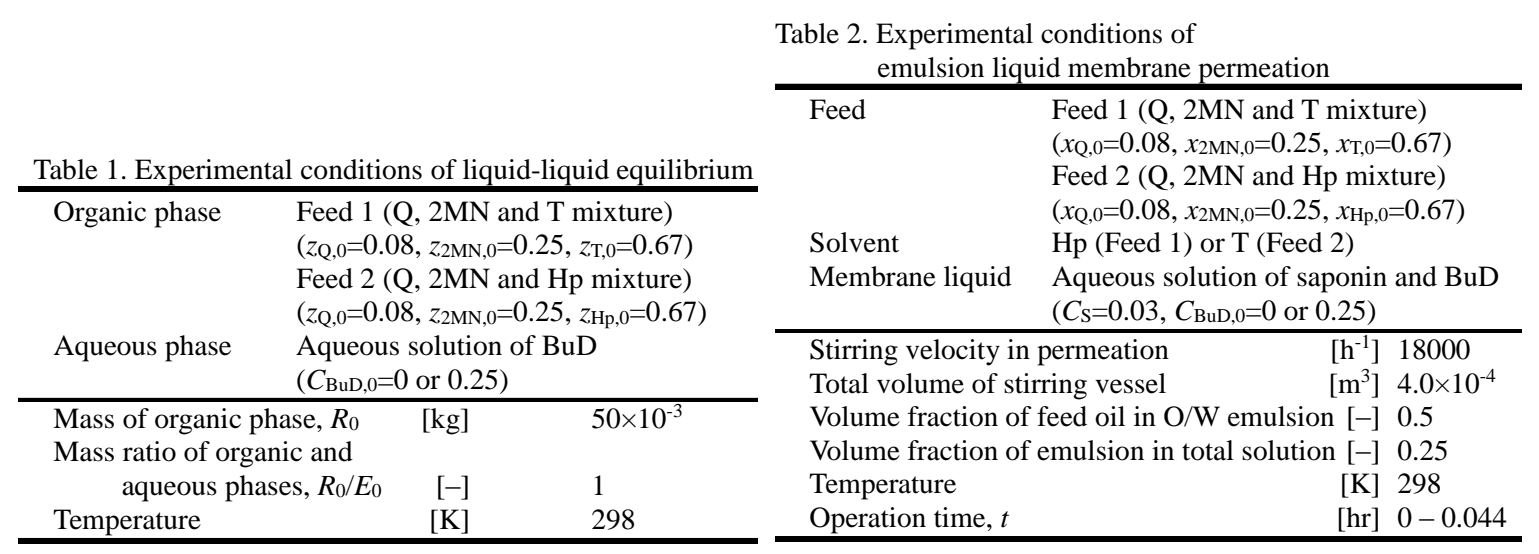

\section{Results and Discussion}

\subsection{Liquid-liquid equilibrium}

The distribution coefficient, $m_{i}$, and separation selectivity, $\beta_{\mathrm{Q}, 2 \mathrm{MN}}$, was defined as,

$$
m_{i}=\frac{C_{i}}{z_{i}}, \quad \beta_{\mathrm{Q}, 2 \mathrm{MN}}=\frac{C_{\mathrm{Q}} / C_{2 \mathrm{MN}}}{z_{\mathrm{Q}} / z_{2 \mathrm{MN}}}\left(=\frac{m_{\mathrm{Q}}}{m_{2 \mathrm{MN}}}\right)
$$

where $C_{i}$ and $z_{i}$ represent the mass fractions of component $i$ in the aqueous and organic phases, respectively. The obtained $m_{i}$ and $\beta_{\mathrm{Q}, 2 \mathrm{MN}}$ values are listed in Table 3. The $m_{i}$ s for quinoline, $m_{\mathrm{Q}}$, were larger than those for 2-methylnaphthalene, $m_{2 \mathrm{MN}}$, in all cases. The $m_{\mathrm{Q}}$ and $m_{2 \mathrm{MN}}$ values for Feed 1 were smaller than those for Feed 2, respectively. The higher polarity feed oil, i.e. the Feed 1 toluene solution, should show lower distribution coefficients than that of the lower polarity solution, i.e. the Feed 2 heptane solution. In the case of Feed 1, toluene being a more polar diluent should dissolve in the aqueous phase and the other polar components, quinolone and methylnaphthalene, will have limited solubility. In the case of Feed 2, the polar components of quinolone and methylnaphthalene should preferentially dissolve in the aqueous phase to make $m_{\mathrm{Q}}$ and $m_{2 \mathrm{MN}}$ larger. This trend was confirmed in the previous studies [6, 9, 11]. The addition of 1,3-butandiol made $m_{i}$ higher, similar to the previous study [10]. The separation selectivity, $\beta_{\mathrm{Q}, 2 \mathrm{MN}}$, was higher with deionized water than that for the aqueous solution of 1,3-butandiol. The addition of 1,3-butandiol had a large influence on the distribution of 2-methylnaphthalene, thus reducing the selectivity. The $\beta_{\mathrm{Q}, 2 \mathrm{MN}} \mathrm{S}$ values for Feed 1 were higher than those for Feed 2 regardless of the additive. 
Table 3. Distribution coefficients and separation selectivity

\begin{tabular}{c|cc|cc}
\hline \multirow{2}{*}{} & \multicolumn{2}{|c|}{$C_{\mathrm{BuD}, 0}=0$} & \multicolumn{2}{c}{$C_{\mathrm{BuD}, 0}=0.25$} \\
& Feed 1 & Feed 2 & Feed 1 & Feed 2 \\
\hline$m_{\mathrm{Q}}$ & $8.9 \times 10^{-3}$ & $9.5 \times 10^{-3}$ & $4.2 \times 10^{-2}$ & $5.2 \times 10^{-2}$ \\
$m_{2 \mathrm{MN}}$ & $7.5 \times 10^{-5}$ & $9.6 \times 10^{-5}$ & $1.3 \times 10^{-3}$ & $2.0 \times 10^{-3}$ \\
$\beta_{\mathrm{Q}, 2 \mathrm{MN}}$ & 118 & 99 & 34 & 26 \\
\hline
\end{tabular}

\subsection{Emulsion liquid membrane permeation}

For all cases, the $(\mathrm{O} / \mathrm{W}) / \mathrm{O}$ emulsion liquid membrane permeations could be stably operated. No phase inversion was observed and the phase separation of the emulsion and extract was readily achieved.

The yield of component $i, Y_{i}$, overall permeation coefficient, $P_{x, i}$, and separation selectivity of quinoline to 2-methylnaphthalene, $\beta_{\mathrm{Q}, 2 \mathrm{MN}}$, were defined in the following equations,

$$
\begin{aligned}
& Y_{i}=\frac{y_{i} \cdot E}{x_{i, 0} \cdot R_{0}}, \quad N_{i}=P_{x, i} \cdot a \cdot\left(x_{i}-\frac{m_{i, \mathrm{E}}}{m_{i, \mathrm{R}}} \cdot y_{i}\right) \cdot V_{\mathrm{T}} \\
& \beta_{\mathrm{Q}, 2 \mathrm{MN}}=\frac{\frac{\mathrm{d}\left(E \cdot y_{\mathrm{Q}}\right)}{\mathrm{d} t} /\left(x_{\mathrm{Q}}-\frac{m_{\mathrm{Q}, \mathrm{E}}}{m_{\mathrm{Q}, \mathrm{R}}} \cdot y_{\mathrm{Q}}\right)}{\frac{\mathrm{d}\left(E \cdot y_{2 \mathrm{MN}}\right)}{\mathrm{d} t} /\left(x_{2 \mathrm{MN}}-\frac{m_{2 \mathrm{MN}, \mathrm{E}}}{m_{2 \mathrm{MN}, \mathrm{R}}} \cdot y_{2 \mathrm{MN}}\right)}\left(=\frac{P_{x, \mathrm{Q}}}{P_{x, 2 \mathrm{MN}}}\right)
\end{aligned}
$$

For the derivation of Eq. (4), the effects of mechanical entrainment and membrane breakage rates caused by membrane instabilities were considered so small as to be negligible relative to those of the permeation rates [11].
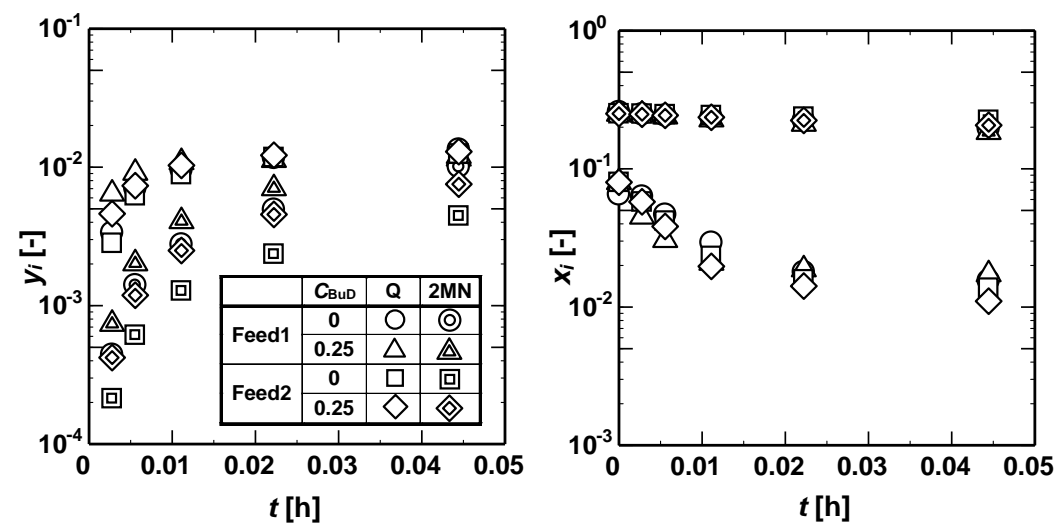

Figure 1. Time courses of $y_{i}$ and $x_{i}$.

Figure 1 shows the time courses of the mass fractions in the raffinate and extract phases, $x_{i}$ and $y_{i}$, respectively. In all cases, the mass fractions of quinoline in the extract phase, $y_{\mathrm{Q}} \mathrm{s}$, were higher than those of 2-methylnaphthalene, $y_{2 \mathrm{MN}} \mathrm{S}$, though $x_{2 \mathrm{MN}, 0}$ was much higher than $x_{\mathrm{Q}, 0}$. The $m_{\mathrm{Q}}$ value was larger than $m_{2 \mathrm{MN}}$ and quinoline could preferably permeate through the emulsion liquid membrane relative to 
2-methylnaphthalene. After around $t=0.02 \mathrm{~h}$, the concentration difference of quinoline in the raffinate and extract phase, $x_{\mathrm{Q}}-y_{\mathrm{Q}}$, was so small and $x_{\mathrm{Q}}$ and $y_{\mathrm{Q}}$ approximately attained plateau values. On the other hand, the concentration difference of 2-methylnaphthalene between the raffinate and extract phases, $x_{2 \mathrm{MN}}-y_{2 \mathrm{MN}}$, was still large at $t=0.02 \mathrm{~h}$, and 2-methylnaphthalene continued to permeate through the emulsion liquid membrane. The addition of 1,3-butandiol to the membrane solution enhanced the permeations of both quinoline and 2-methylnaphthalene through the emulsion liquid membrane. This was because the distribution coefficients of the permeates increased by addition of 1,3-butandiol in the membrane solution, as mentioned above. The permeation of quinoline and 2-methylnaphthalene were affected by the type of the feed solution, and the permeation rate was a little larger with Feed 1, than that with Feed 2.

Figure 2 shows the time courses of yield of component $i, Y_{i} . Y_{\mathrm{Q}}$ was much higher than $Y_{2 \mathrm{MN}}$ and the emulsion liquid membrane could effectively separate these two components. The yields were higher with 1,3-butandiol than those without 1,3-butandiol. The permeation rate of quinoline was large in the initial stage relative to the rate of 2-methylnaphthalene. In the range of $t>0.02 \mathrm{~h}$, the concentration difference of quinoline became small thus reducing the permeation rate and attained plateau values for each condition. In the case of 2-methylnaphthalene, large concentration differences were maintained during the permeation runs, and the yields linearly increased in all cases. $Y_{\mathrm{Q}}$ attained a values greater than 0.9 for Feed 1, though $m_{i}$ was smaller with the toluene feed oil solution than that with the heptane solution.

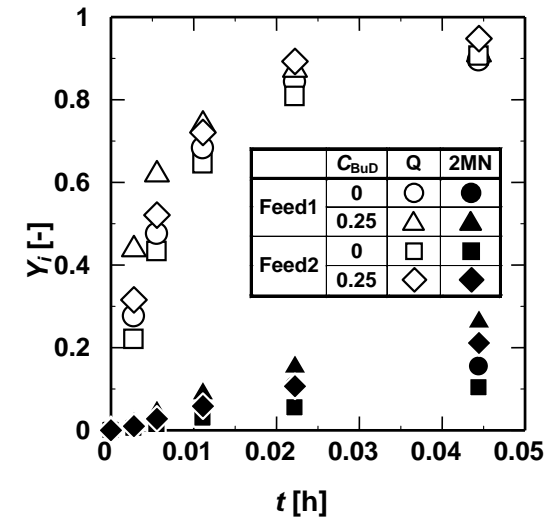

Figure 2. Time courses of $Y_{i}$.

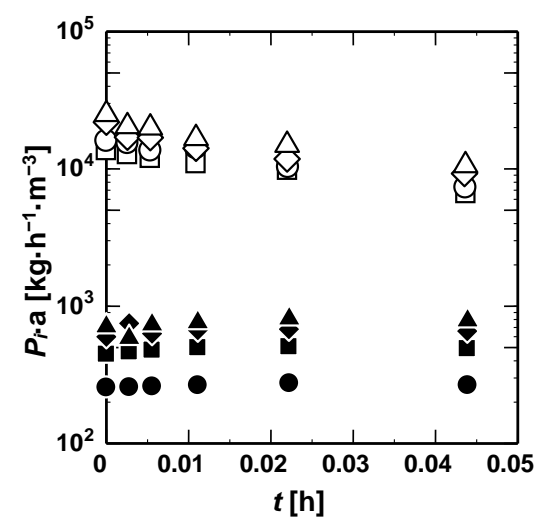

Figure 3. Time courses of $P_{x, i} \cdot a$. (keys are same as in Figure 2)

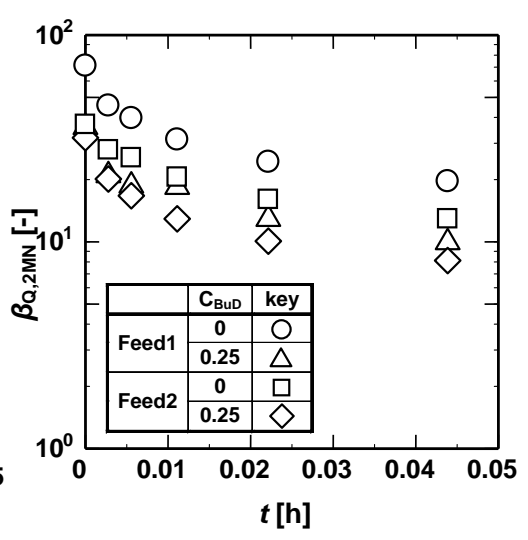

Figure 4 . Time courses of $\beta_{\mathrm{Q}, 2 \mathrm{MN}}$.

Figure 3 shows the time courses of the overall volumetric permeation coefficient of component $i$, $P_{x, i} \cdot a$, estimated by Eq. (4). The $P_{x, i} \cdot a$ value for quinoline was larger than that for 2-methylnaphthalene. The addition of 1,3-butandiol to the membrane solution enhanced both quinoline and 2-methylnaphthalene $P_{x, i} \cdot a$ values. The overall permeation coefficient, $P_{x, i}$, for a one dimensional monolayer liquid membrane [11] can be expressed as;

$$
P_{x, i} \propto \frac{\rho_{\mathrm{M}} \cdot D_{i} \cdot m_{i, \mathrm{R}}}{\delta}
$$

$P_{x, i}$ should be proportional to the distribution coefficient, however $P_{x, i} a$ was larger for Feed 1 than that for Feed 2 though $m_{i}$ was smaller for Feed 1. This might occur because of the conditions of $(\mathrm{O} / \mathrm{W}) / \mathrm{O}$ 
dispersion. The properties of the $\mathrm{O} / \mathrm{W}$ emulsion should be affected by the properties of the inner oil, and accordingly the $(\mathrm{O} / \mathrm{W}) / \mathrm{O}$ dispersion should change the specific surface area in the vessel, $a$. The measurement of the $(\mathrm{O} / \mathrm{W}) / \mathrm{O}$ dispersion is necessary to clarify the permeation mechanism.

Figure 4 shows the time courses of the separation selectivities of quinoline relative to 2-methylnaphthalene, $\beta_{\mathrm{Q}, 2 \mathrm{MN}}$, estimated by Eq. (5). The $\beta_{\mathrm{Q}, 2 \mathrm{MN}}$ value was reduced by the addition of 1,3-butandiol. The addition of 1,3-butandiol enhanced not only quinoline permeation but also 2-methylnaphthalene permeation. The selectivity was larger with Feed 1 than with Feed 2. This trend conformed with the results of the distribution coefficients measured in the liquid-liquid equilibrium, and the effects of the material system also influenced the selectivity.

\section{Conclusion}

The separation of nitrogen heterocyclic compound from a model oil by the emulsion liquid membrane technique was studied. The distribution coefficient of quinoline was larger than that of 2-methylnaphthalene. The coefficients were larger with the feed solution rich in heptane than those with the solution rich in toluene. 1,3-Butandiol, used as an additive, enhanced the distribution coefficients of both components but reduced the separation selectivity. In the case of the emulsion liquid membrane separation, quinoline preferably permeated through the emulsion liquid membrane, and could be separated relative to 2-methylnaphthalene in the model feed oils. The addition of 1,3-butandiol enhanced the permeation rates of both components. The rates were larger with the toluene feed oil than those with the heptane solution probably because the specific surface area in the $(\mathrm{O} / \mathrm{W}) / \mathrm{O}$ dispersion might have been larger with the toluene solutions. The separation selectivity of quinoline relative to 2-methylnaphthalene decreased with the addition of 1,3-butandiol, and it was larger with the heptane feed solution compared to that for the toluene feed solution, which followed the trend of the distribution coefficients. For clarification of the permeation mechanism it is necessary to study not only the permeation rates of the components, but also the $(\mathrm{O} / \mathrm{W}) / \mathrm{O}$ dispersion.

\begin{tabular}{|c|c|c|c|c|}
\hline \multicolumn{5}{|c|}{ Nomenclature } \\
\hline$a$ & $=$ specific surface area & $y_{i}$ & $=$ mass fraction of component $i$ in extract phase & {$[-]$} \\
\hline$C_{i}$ & $=$ mass fraction of component $i$ in aqueous or & & $=$ mass fraction of component $i$ in organic phase & \\
\hline$D$. & $\begin{array}{l}\text { membrane phase } \\
=\text { diffusivity of component } i \text { in membrane liquid }\left[\mathrm{m}^{2} \mathrm{~h}^{-1}\right]\end{array}$ & $\begin{array}{l}\beta_{\mathrm{Q}, 2 \mathrm{MN}} \\
\delta\end{array}$ & $\begin{array}{l}=\text { separation selectivity of } \mathrm{Q} \text { relative to } 2 \mathrm{MN} \\
=\text { effective thickness of liguid membrane }\end{array}$ & {$[-]$} \\
\hline$E$ & $=$ mass of extract phase $\quad[\mathrm{kg}]$ & $\rho_{\mathrm{ML}}$ & $=$ density of the liquid membrane & {$\left[\mathrm{kgm}^{-3}\right]$} \\
\hline$m_{i}$ & $=$ distribution coefficient of component $i$ & & & \\
\hline$N$ & $=$ permeation rate & Subsc & ript> & \\
\hline$P_{x, i}$ & $=$ overall permeation coefficient of component $i$ & 0 & $=$ at initial state & \\
\hline & {$\left[\mathrm{kgh}^{-1} \mathrm{~m}^{-2}\right]$} & $2 \mathrm{MN}$ & $=2$-methylnaphthalene & \\
\hline$R$ & $=$ mass of raffinate phase & $\mathrm{Hp}$ & $=$ heptane & \\
\hline$V_{\mathrm{T}}$ & $=$ total volume of vessel & $i$ & $=$ component $i$ & \\
\hline$x_{i}$ & $=$ mass fraction of component $i$ in raffinate phase & Q & = quinoline & \\
\hline$Y_{i}$ & $=$ yield of component $i$ & $\mathrm{~T}$ & $=$ toluene & \\
\hline
\end{tabular}

\section{References}

1) B.D. Batts, A.Z. Fathoni, Energy Fuels, 5, 2-11 (1991).

2) D. Bohlmann, E. Dohler, H. Limmer, J. Chem. Technol., 33, 358-364 (1981).

3) M.A. Wecher, D.R. Hredy, Fuel Sci. Technol. Int., 7, 423- (1989). 
4) J. Qi, Y. Yan, Y. Su, F. Qu, Y. Dai, Energy Fuels, 12, 788-791 (1998).

5) M. Matsumoto, Y. Inomoto, K. Kondo, J. Membr. Sci., 246, 77-81 (2005).

6) C. Salim, J. Saito, R. Egashira, J. Jpn. Pet. Inst., 48, 60-66 (2005).

7) C. Salim, R. Egashira, J. Jpn. Pet. Inst., 49, 326-334 (2006).

8) R. Egashira, K. Watanabe, Solvent Extr. Res. Dev., Jpn., 14, 63-69 (2007).

9) R. Egashira, N. Hara, M. Nagai, 7th World Congress of Chemical Engineering C23-004 (2005).

10) H. Habaki, B. Dejin, R. Egashira, ICSST08 FP-07 (2008).

11) Y. Shimada, D. Bi, H. Habaki, R. Egashira, J. Chem. Eng. Jpn, 46, 376-382 (2013).

12) H. Habaki, M. Haruna, R. Egashira, J. Jpn. Pet. Inst., 56, 304-311 (2013). 